\title{
Perfil docente de licenciados em Química em uma universidade pública cearense
}

\author{
Teacher profile of teachers degree in Chemistry at a public university in \\ Ceará \\ Perfil docente de egresos en química de una universidad pública de \\ Ceará
}

\author{
Francisco Ranulfo Freitas Martins Júnior (ranulfo.freitas@uece.br) \\ Universidade Estadual do Ceará-UECE
}

José Airton de Freitas Pontes Junior (jose.airton@uece.br)

Universidade Estadual do Ceará-UECE

Eloisa Maia Vidal (eloisamvidal@yahoo.com.br)

Universidade Estadual do Ceará-UECE

Resumo: Tornar-se professor pode ser considerado um processo complexo e peculiar a cada indivíduo que opta por seguir a profissão. No entanto, algumas características podem ser apontadas para vislumbrar a docência como atividade profissional. Este artigo objetiva identificar o perfil docente de licenciados em Química em uma universidade pública cearense, no período 2008 - 2018, expondo fatores associados às suas vivências pessoais e profissionais por meio de análise com estatística descritiva. Os egressos são professores de Ciências/Química na Educação Básica, tendo vislumbrado a docência como profissão, sobretudo, pela opção de prestar vestibular em curso da área das Ciências da Natureza. Eles ingressaram na licenciatura em Química da instituição, considerando-a, em determinada medida, formação profissional adequada. Em sua maioria, realizaram formação continuada na mesma área da graduação e potencializam seu ensino mediante a mobilização de diferentes saberes. Conclui-se que, dos distintos períodos geradores de aprendizagens da docência, derivam-se indícios de constituição profissional.

Palavras-chave: licenciado em Química; aprendizagem docente; tornar-se professor; constituição profissional.

Abstract: Becoming a teacher can be considered a complex and peculiar process for each individual who chooses to follow the profession. However, some characteristics can be pointed out to glimpse teaching as a professional activity. This paper aims to identify profile of teachers degree in Chemistry at a public university in Ceará, in the decade 2008 - 2018, measuring factors associated with their personal and professional experiences through analysis with descriptive statistics. The graduates are teachers of Science/Chemistry in basic education, having envisioned teaching as a profession, 
above all, due to the option of taking a university entrance exam in the field of Natural Sciences. They entered the institution's teaching degree in Chemistry, considering it, to a certain extent, adequate professional training. Most of them have undergone continuing education in the same area as graduation and enhance their teaching through the mobilization of different knowledge. It is concluded that, from the different periods that producers learnings of teaching, evidence of professional constitution is derived.

Keywords: teacher degree in Chemistry; teacher learning; become a teacher; professional constitution.

Resumen: Convertirse en maestro puede considerarse un proceso complejo y peculiar para cada individuo que elige seguir la profesión. Sin embargo, algunas características pueden señalarse para vistazo la enseñanza como una actividad profesional. Este artículo tiene como objetivo identificar el perfil docente de los licenciados en Química de una universidad pública de Ceará, en la década 2008 - 2018, midiendo factores asociados a sus experiencias personales y profesionales mediante análisis con estadística descriptiva. Los egresos son profesores de ciencias/química en la educación básica, habiendo vislumbrado la enseñanza como profesión, especialmente a través de la opción de hacer el examen de ingreso en un curso del área de Ciencias Naturales. Ingresaron en la carrera de Química de la institución, por considerarla, en cierta medida, una formación profesional adecuada. La mayoría de ellos tenían formación continua en la misma área que la licenciatura, y mejoran su enseñanza mediante la movilización de diferentes conocimientos. Se concluye que, de los diferentes periodos que generan aprendizajes sobre la enseñanza, se derivan indicios de constitución profesional.

Palabras-clave: licenciatura en Química; aprendizaje de profesores; convertise en profesor; constitución profesional.

\section{INTRODUÇÃO}

Tornar-se professor perpassa a vida de um indivíduo, sendo resultado de motivações intrínsecas e extrínsecas a escolha pela docência (NASCIMENTO, 2002) e podendo ocasionar estabilidade profissional. Para enveredar por esse caminho, é preciso identificação com determinada área de conhecimento em que se deseja atuar, por empatia com seus conteúdos e momentos de interação com estes durante estudos em níveis de Educação Básica e Superior. Percebe-se, ainda, que experiências vivenciadas em diferentes momentos da formação inicial (antes, durante e após) são fundamentais na construção de uma identidade profissional (DUBAR, 2005; FIGUEIRA-OLIVEIRA; ANJOS; RÔÇAS, 2020), corroborando também na inserção e permanência na carreira docente, fatores que, segundo Castro e Carvalho (2019), são fundamentais à valorização docente, remuneração e atratividade pelo magistério. 
Por exemplo, na área das Ciências da Natureza, além das motivações citadas, tal acontecimento pode surgir da vontade de ensinar outrem a ler, interpretar e compreender fenômenos naturais do mundo, resolver problemas e contribuir com o progresso científico, tecnológico e ambiental da sociedade (CHASSOT, 2018). Ademais, ele pode ser desencadeado pelo incentivo de professores formadores em curso de licenciatura (SÁ; SANTOS, 2016), e consolidado pela prática docente.

Considerando as circunstâncias que podem contribuir com a constituição profissional do professor, o objetivo deste artigo, oriundo de uma pesquisa de doutorado em desenvolvimento, é identificar o perfil docente de egressos da licenciatura em Química de uma instituição pública cearense, no decênio 2008 - 2018.

\section{2. ÉPOCAS INCISIVAS DE APRENDIZADO DA DOCÊNCIA}

Constituir-se professor envolve a aquisição de diferentes habilidades e competências específicas ao ensino e inerentes à configuração identitária (DUBAR, 2012) desse profissional. Fatores que acarretam o aprendizado da docência se acumulam ao longo de trajetórias de vida pessoal e profissional de quem aspira ser professor. Esse processo de constituição docente pode ser manifestado por meio de relatos textuais produzidos a partir de diferentes instrumentais, como, por exemplo, a narrativa (RADETZKE, 2019).

Nesse sentido, Tardif e Raymond (2000) entendem que a aprendizagem do trabalho no magistério é resultado da apropriação de saberes docentes (temporais, plurais e heterogêneos $)^{1}$ ao longo do tempo. Segundo Dubar (2005), os momentos que corroboram com a construção de uma identidade profissional são associados à história de vida, englobando experiências familiares, escolares, culturais etc., característicos de uma socialização primária; assim como formação acadêmica (inicial e continuada) e carreira profissional, relativas à socialização secundária.

As aprendizagens que o professor adquire sobre a docência são de origem social (TARDIF; RAYMOND, 2000; TARDIF, 2002) e fundamentais para a realização de seu

\footnotetext{
${ }^{1}$ Tardif e Raymond (2000) afirmam que os saberes docentes são construídos ao longo da história de vida do professor (temporais), sendo variados (plurais), diferentes entre si (heterogêneos) e dos tipos pessoal, da formação escolar, da formação profissional para o magistério, dos programas e livros didáticos usados no trabalho, da experiência na profissão, na sala de aula e na escola.
} 
trabalho. A aprendizagem inicial (pré-profissional) ocorre antes do ingresso na profissão docente. Sucedendo esta, em formato contínuo e acumulativo, desenvolve-se a aprendizagem profissional, originada em curso de formação inicial, aprimorada em formação permanente e potencializada enquanto se exerce a docência.

Por meio da socialização primária ao longo de suas primeiras décadas de vida, o individuo aprende a ser sociável, principalmente no convívio familiar e no universo institucional da escola. Já na socialização secundária há evolução de sua maturidade, pelo fato de estar sob influência de espaços sociais nos quais passa a interagir por conta de sua profissão, como faculdade e ambiente de trabalho (DUBAR, 2012). A complementação das socializações primária e secundária impulsiona o progresso social, expresso em percursos formativos e profissionais, individuais e/ou institucionais.

A trajetória formativa tem início em curso de formação universitária, que Nóvoa (1999) defende como processo fundamental que fomentou a profissionalização do ensino desde meados do século XVI, estando legitimada em conhecimento específico. O ambiente de formação inicial tende a propiciar iniciativas destinadas à preparação para o ensino, condicionando o futuro professor a interconectar suas dimensões pessoais e profissionais, imbricando-as em sua personalidade (NÓVOA, 1992). Se atendo a essa premissa, Nóvoa (2017) entende que a profissão docente deva ser produzida no âmbito das escolas de formação de professores. Ele alega que é preciso diálogo entre as assunções acerca desse tipo de formação e o efetivo trabalho desempenhado pelo professorado no ambiente escolar, sobretudo em sala de aula, que para Oliveira (2004), pode acarretar profissionalização.

Destarte, não haverá hiato entre as dinâmicas escolar e universitária, diminuindo as dificuldades impostas aos professores por causa das múltiplas facetas do trabalho docente, principalmente no início da carreira (HUBERMAN, 1995). Isto corroborará com o desenvolvimento profissional autônomo, e contrariará, de acordo com Nóvoa (1992), um modelo de formação dual que separa saberes acadêmicos e práticos. No entanto, é preciso que haja consciência em relação aos diferentes elementos constituintes da profissão docente e sua integração no trabalho (TARDIF; RAYMOND, 2000), bem como, consonância entre formação inicial e atuação profissional (INEP, 2014). 
Após ter sido devidamente habilitado para exercer sua profissão, e saber refletir criticamente sobre a própria prática, dotada de diferentes saberes sustentadores e validadores de seu trabalho (TARDIF, 2002), o professor pode buscar capacitação mediante qualificação de sua capacidade laboral. Ela pode ser efetivada pelo domínio e execução de saberes profissionais adquiridos em formação, por experiência e aprendizagem no magistério, viabilizadas por meio de interações com alunos, pares de profissão e outros partícipes do ambiente escolar, como advogam Tardif e Lessard (2014).

A formação continuada realizada ao longo do trabalho é tão importante quanto à formação inicial. E a carreira profissional, atividade com relevância similar a formação docente, é capaz de consolidar saberes formalizados e habilidades correspondentes, como aponta Dubar (2005). São estes os motivos responsáveis pela crença de que a aprendizagem de qualquer profissão ocorre ao longo da vida ativa, tanto durante a socialização primária como após ela, pela formação profissional desencadeada no exercício profissional contínuo. Por exemplo, as fases do aprendizado da docência na área de Ciências da Natureza se expressam no ensino de disciplinas científicas, portadoras de peculiaridades que as tornam imprescindíveis para a compreensão do mundo natural (CACHAPUZ et al., 2011; CHASSOT, 2018). Tais momentos estimulam a profusão de saberes docentes e, por isto, devem balizar a formação na área que tem atraído sujeitos interessados pela docência, dentre outros, por afetividade e identificação com a ciência, carência de docentes e praticidade e aplicação de conhecimentos científicos (SÁ; SANTOS, 2016).

Tendo supridas suas necessidades formativas (CARVALHO; GIL-PÉREZ, 2011) no âmbito da formação inicial, e visando se firmar na profissão docente (NÓVOA, 2017) por meio de formação continuada e aprimoramento de sua prática, o professor de Ciências da Natureza qualifica-se a desempenhar o ensino. Os esforços empreendidos para tornar didáticos os conhecimentos científicos, molda a identidade docente à medida que tal professor adquire experiência profissional.

No contexto do ensino das ciências, condiciona-se o professor, também, a adquirir competências para transpor didaticamente conteúdos científicos, utilizando um repertório de aprendizagens provenientes de saberes profissionais (TARDIF, 2002). Ao 
se capacitar continuamente para desempenhar sua profissão, este profissional articula conhecimentos específicos e pedagógicos adquiridos em formação em curso de licenciatura (SILVA; OLIVEIRA, 2009), sob contínuas orientações das Diretrizes Curriculares Nacionais (DCN) para a formação de professores (BRASIL, 2002a, 2015, 2019), inclusive na área de Química (BRASIL, 2001), norteando ainda sua prática pedagógica em conformidade com orientações curriculares para a Educação Básica (BRASIL, 1997, 2000, 2002c, 2006, 2018) emanadas após a promulgação da Lei de Diretrizes e Bases da Educação Nacional (LDB nº 9.394/96).

Maldaner (2013) complementa essas assertivas afirmando que o professor de Química pode ser estimulado a aumentar sua capacidade de produzir aulas de Química visando o efetivo aprendizado de seus alunos e, por consequência, sua própria profissionalidade. Segundo o autor, ao refletir sobre o trabalho que desenvolve, inerente a realidade vivenciada em sala de aula, esse professor poderá responder as demandas cotidianas oriundas dos processos de ensino e aprendizagem em Química, tornando-se um investigador de sua prática e se colocando em evolução. Além de envolver aspectos relacionados ao aprendizado da docência, ser professor de Química, como mencionado, focaliza peculiaridades passíveis de investigação, como apresentado a seguir.

\section{PROCEDIMENTOS METODOLÓGICOS}

Procurando definir alguns dos parâmetros essenciais que delineiam o "tornar-se professor", aludindo-o a um perfil docente constituído por variáveis atinentes a distintos momentos de vida, foi desenvolvido um estudo de caso do tipo único e instrumental (YIN, 2015), referindo-o a um só contexto real no mundo contemporâneo, para responder a seguinte indagação: Em que medida determinados licenciados em Química estão se constituindo professores?

Esta questão circunscreve-se a um curso de licenciatura em Química de uma universidade pública estadual localizada no interior do Estado do Ceará, do qual a amostra (egressos) foi gerada. O estudo de caso é justificado pelo fato de se tratar de uma realidade de formação de professores de Química, incluindo suas contradições entre a demanda por docentes e os problemas de evasão vivenciados pelo curso. Portanto, estudá-lo faz parte da análise de contexto para melhoria da prestação de serviço da universidade na região. 
A quantificação de aspectos relativos a convívio familiar e social, fase escolar, vestibular, formação inicial, formação contínua e prática docente, permite uma visão geral sobre os sujeitos, conferindo abrangência, objetividade e precisão na busca pelo perfil docente almejado. Nessa lógica, o enfoque quantitativo suporta esta pesquisa, pois segundo Sampieri, Collado e Lucio (2013), tal abordagem sustenta-se em um conjunto de processos que visam solucionar um problema concreto, como: a) definição e seleção da amostra e de suas variáveis; b) coleta e análise dos dados; c) comunicação do relatório.

Para interação com o campo de pesquisa, almejando compreender sua capacidade de formar licenciados e designá-los para a profissão docente, foram realizados procedimentos fundados na complexidade e particularidade de uma investigativa casuística, como preconiza Stake (1995).

Selecionado o recorte temporal 2008 - 2018, relativo ao período entre o primeiro ano de colação de grau no curso em questão e a qualificação do projeto de doutoramento do qual este trabalho foi derivado, obteve-se uma população de 122 egressos. Após validação por pré-testagem junto a cinco sujeitos com perfil semelhante aos selecionados, um questionário eletrônico de 56 questões (Google Forms®) foi enviado, em janeiro de 2020, a população escolhida para seleção amostral, cujo critério é a atuação na Educação Básica como professor(a) de Ciências/Química. É importante destacar que os sujeitos ficaram cientes das pretensões da pesquisa, assinando um Termo de Consentimento Livre e Esclarecido (TCLE).

O Questionário foi estruturado em dois blocos temáticos envolvendo os seguintes aspectos: a) aprendizagem pré-profissional e b) aprendizagem profissional da docência (TARDIF; RAYMOND, 2002); contemplando características de natureza pessoal, familiar, cultural e escolar, formações inicial e continuada e exercício docente. Houve ainda a necessidade de investigar as experiências dos sujeitos quando da submissão ao processo seletivo (vestibular) para o curso de licenciatura em Química da instituição, bem como a trajetória acadêmica nesse curso. Desse modo, em fevereiro de 2020, houve o recolhimento do histórico escolar de graduação de cada um, no qual constam informações sobre notas das provas da segunda e última fase do vestibular (conhecimentos específicos) e parâmetros do curso como fluxo e conteúdos 
curriculares, disciplinas cursadas por semestre (com notas e frequências) e índices acadêmicos [créditos obtidos, Índice de Qualificação Discente (IQD) e Média de Nota Parcial de Conhecimento (NPC)].

Os dados extraídos do Questionário e do Histórico Escolar foram organizados categoricamente em planilha do Microsoft Excel® e, em sequência, analisados por meio de estatística descritiva com auxílio do software Jasp 0.8.6.0®, em termos de frequência, medidas de tendência central, variabilidade e probabilidade e curva normal, como orienta Levin, Fox e Forde (2012). O Quadro 1 apresenta as temáticas respectivas as dezoito variáveis utilizadas na pesquisa e provindas de ambos os instrumentos.

Quadro 1. Temáticas das variáveis analíticas, por instrumental.

\begin{tabular}{|c|c|c|c|}
\hline & Dados Pessoais & $\begin{array}{c}\text { Aprendizagem pré- } \\
\text { profissional }\end{array}$ & Aprendizagem profissional \\
\hline \multirow{3}{*}{ Questionário } & \multirow{3}{*}{$\begin{array}{l}\text { 1. Atuação } \\
\text { profissional } \\
\text { 2. Estado civil } \\
\text { 3. Renda } \\
\text { 4. Estudos no } \\
\text { ensino médio }\end{array}$} & \multirow{3}{*}{$\begin{array}{l}\text { 7. Experiência e } \\
\text { influência na escolha da } \\
\text { profissão docente } \\
8 \text {. Aspectos do } \\
\text { vestibular }\end{array}$} & $\begin{array}{l}\text { Formação inicial: } \\
\text { 10. Preparação para a docência }\end{array}$ \\
\hline & & & $\begin{array}{l}\text { Formação continuada: } \\
\text { 11. Realização } \\
\text { 12. Escolaridade } \\
\text { 13. Área de Formação }\end{array}$ \\
\hline & & & $\begin{array}{l}\text { Exercício docente: } \\
\text { 13. Experiência } \\
\text { 14. Atuação } \\
\text { 15. Características do trabalho docente. }\end{array}$ \\
\hline Histórico & $\begin{array}{l}\text { 5. Sexo } \\
\text { 6. Idade } \mathrm{Are}\end{array}$ & $\begin{array}{l}\text { 9. Notas na } 2^{a} \text { fase do } \\
\text { vestibular }\end{array}$ & $\begin{array}{l}\text { Formação inicial: } \\
\text { 16. Fluxo } \\
\text { 17. Tempo de curso } \\
\text { 18. Desempenho acadêmico }\end{array}$ \\
\hline
\end{tabular}

Fonte: Elaboração própria.

O conjunto dessas variáveis abrange o perfil docente investigado, contemplando alguns dos momentos vivenciados pelos sujeitos e que interferiram decisivamente em sua constituição profissional.

\section{PERFIL DOCENTE DE LICENCIADOS EM QUÍMICA}

Dentre a população referente ao período 2008 - 2018, 90\% consentiu, livre e de modo esclarecido, em participar da pesquisa e, assim, responderam o Questionário. Do total, 50\% deles atendeu ao critério de seleção da amostra - atuar na Educação Básica como professor de Ciências/Química, fato que endossa a dificuldade da licenciatura em Química no Brasil em suprir a demanda necessária de professores para este nível educacional (SÁ; SANTOS, 2016). O grupo analisado é composto de $63 \%$ de mulheres; 
$89,9 \%$ se dedicam exclusivamente ao ensino, e o restante $(11,1 \%)$ exerce outra profissão além da docência. Sendo brasileira, principalmente cearense, a maioria tem entre 30 e 39 anos (74\%), é casada (55,6\%), não tem filho (46,3\%) e possui renda familiar de até 2,5 salários-mínimos (52\%). Todos frequentaram o Ensino Médio em escola regular, principalmente na rede pública de ensino (85\%).

Esses primeiros resultados demonstram que, mesmo quando alguém opta por cursar uma licenciatura, a inserção na carreira docente não é uma escolha natural. É preciso que se atente aos candidatos a professor (NASCIMENTO, 2002) com o intuito de estimular-lhes o ingresso e a permanência na profissão docente (CASTRO; CARVALHO, 2019) e, ao se tornarem profissionais, é importante dar-lhes oportunidades para expressarem como vem se dando seu desenvolvimento profissional (RADETZKE, 2019).

\subsection{Aprendizagem pré-profissional}

O aprendizado da docência antes do ingresso na licenciatura em Química pode estar associado a fatos familiares, culturais e da vida estudantil. Embora a maioria $(68,5 \%)$ tenha afirmado que a escolha da profissão não teve influência de nenhum tipo de experiência provinda desses fatos, $33,4 \%$ respondeu que a motivação resultou da precocidade em ensinar $(11,2 \%)$, por influência de seus professores na escola, de familiares e outros fatores associados a atividades diversas (7,4\%, cada).

Com efeito, Tardif e Raymond (2000) relatam que os professores têm dificuldade de expressar claramente circunstâncias de vida que acarretaram a escolha pelo magistério antes do ingresso em curso universitário, devido às muitas rupturas e continuidades vivenciadas em sua trajetória de vida. Os autores salientam que, os saberes pré-profissionais não são inatos, mas das experiências tácitas dos sujeitos, enquanto interagem com outros e, então, fomentam sua identidade pessoal e social.

Sobre a época do vestibular, os egressos relataram que o gosto pelas disciplinas da área de Ciências da Natureza (80\%) influenciou na tentativa de ingresso em cursos de graduação nesta área ou em áreas afins. Esse foi o principal motivo pela opção de ingresso no curso em análise, embora, para a maioria (63\%), este curso não foi a primeira opção. As Figuras 1 e 2 elucidam o desempenho na segunda fase do vestibular 
para o curso ao qual se graduaram, assim como, reafirmam seu gosto por disciplinas científicas, principalmente, Biologia e Química.
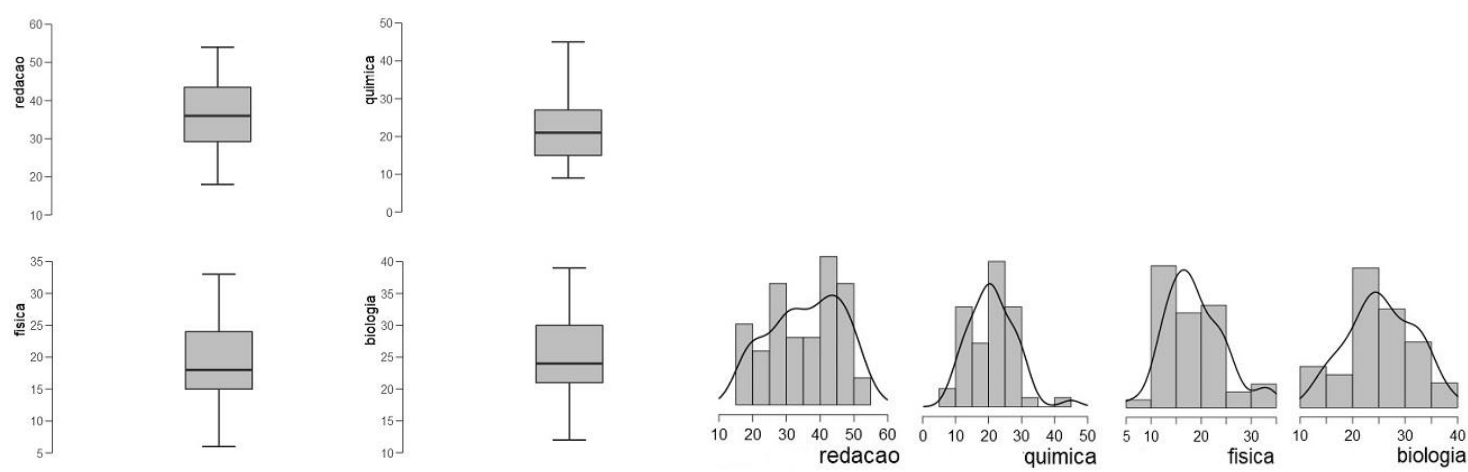

Figura 1 - Distribuição quartílica.

Figura 2 - Distribuição normal.

Fonte: Elaboração própria com auxílio do Jasp 0.8.6.0®, baseada nos dados do Histórico Escolar.

O melhor desempenho foi na prova de Redação, cuja média atingiu 35,7 pontos, seguido de Biologia (25,5 pontos), Química (21,1 pontos) e Física (18,8 pontos). O desempenho mais regular foi em Química, pois seu box-plot é o mais achatado, indicando diferença interquartílica $\left(\mathrm{Q}_{3}-\mathrm{Q}_{1}\right)$ de apenas 13 pontos. Todas as distribuições adequam-se a uma curva normal, concentrando a maioria das notas a um desvio padrão acima ou abaixo da média. Entretanto, esses resultados indicam que a média desse desempenho (25,8 pontos) está abaixo de $50 \%$, pois de acordo com informações da comissão executiva do vestibular da instituição, a pontuação máxima em cada prova é de 60 pontos.

Os resultados obtidos, tanto no Questionário quanto no Histórico Escolar, permitem inferir que a aprendizagem pré-profissional da docência é um momento de confirmação da escolha por esta profissão, corroborando com a construção da identidade profissional (DUBAR, 2005) na medida em que o sujeito vai se identificando com os aspectos teóricos do ensino.

\subsection{Aprendizagem profissional}

Obtido após a aprendizagem pré-profissional, o aprendizado profissional da docência circunscreve um período desde o ingresso na licenciatura em Química até o exercício da docência em meados do início do ano de 2020, incluindo a formação continuada após a conclusão da graduação. Sendo assim, foram mensurados: 1) O 
desempenho no curso de graduação e a opinião deles sobre a eficiência do mesmo em preparar para atuação na Educação Básica; 2) Envolvimento com atividades de formação continuada; 3) Aspectos do trabalho docente que realizam.

Sendo a parte mais densa de sua constituição profissional, esta aprendizagem dota o professor de inúmeras habilidades e competências correspondentes ao ensino (TARDIF, 2002), agregando valor à profissão docente pela imbricação entre formação e atuação profissional (NÓVOA, 2017), como se apresenta doravante.

\subsubsection{Formação inicial}

O curso de licenciatura em Química no qual os professores colaram grau iniciou suas atividades administrativas e acadêmicas no ano de 2004, possuindo os fluxos curriculares $^{2} 2002.1$ e 2008.2. Eles estão presentes na Proposta Pedagógica do Curso (PPC), atendendo ao que está preconizado tanto nas DCN de formação de professores (BRASIL, 2002) como na do curso de Graduação em Química - Licenciatura (BRASIL, 2001). Até o ano de 2014, $61 \%$ dos pesquisados realizaram seus estudos no fluxo curricular 2002.1, em até quatro anos (2004 - 2007), e 39\% estudaram com base no fluxo curricular 2008.2, em até oito anos (2007 - 2014).

Sobre o tempo de concluir o curso, 94\% dos pertencentes ao fluxo 2002.1 se formou no quinquênio 2008 - 2013, com uma duração média de 10 semestres, considerando 2,8 semestres de desvio padrão e um intervalo de 7 a 18 semestres. Todos pertencentes ao fluxo 2008.2 se formaram no quinquênio 2012 - 2017, com uma duração média de 11 semestres, considerando 2,1 semestres de desvio padrão e um intervalo de 8 a 16 semestres. Vale salientar que, ampla maioria dos professores pertencentes a ambos os fluxos extrapolaram o tempo máximo de conclusão de curso (8 semestres) estabelecido pelas diretrizes já mencionadas (BRASIL, 2002a, b).

Questionados sobre a efetividade do curso em formar professores para a Educação Básica, 55,5\% se sentiu indecisa em relação a isto, 35,2\% informou que sim e 9,3\% que não houve preparação nesse sentido. Esse sentimento de negação ou indecisão se deu,

\footnotetext{
${ }^{2}$ As diferenças entre os fluxos são a quantidade de carga horária e créditos para integralização curricular (2002.1 = 2.910 horas e 164 créditos; 2008.2 = 3.094 horas e 182 créditos), a substituição da prática de ensino pelo estágio supervisionado e a redistribuição e diminuição da quantidade de disciplinas nos componentes curriculares.
} 
principalmente pela: a) falta de estudo da realidade enfrentada pelo professor enquanto atua em sala de aula $(51,4 \%)$; b) compreensão do funcionamento da Educação Básica $(26,3 \%)$; c) incentivo no curso, seja por parte dos professores formadores $(13,1 \%)$ ou por escassez de aulas práticas/experimentais no laboratório $(7,9 \%)$.

Foi possível analisar as notas que eles obtiveram em todos os componentes curriculares do curso e, assim, estabelecer uma relação com a sua opinião sobre a preparação aludida, considerando: 1) Conteúdo Básico Instrumental (CBI); 2) Conteúdo Básico Específico (CBE); 3) Formação Pedagógica (FP); 4) Prática como Componente Curricular (PCC); 5) Prática de Ensino de Química/Estágio Supervisionado (PEQ/ES); 6) Optativas (OPT).

É importante destacar que as médias de créditos obtidos por ambos os grupos de professores no curso (2002.1 e 2008.2), um dos índices acadêmicos analisados, esteve em conformidade ao exigido pela instituição, sendo 164 créditos e 186 créditos, com desvio padrão de 2,5 e 3,2, respectivamente. O desempenho acadêmico deles no curso foi calculado com base em suas notas nos componentes curriculares e nos demais índices acadêmicos (média das médias da $\mathrm{NPC}^{3}$ e $\mathrm{IQD}^{4}$ ), conforme apresentado no Quadro 2.

Quadro 2. Medidas de tendência central dos componentes curriculares e índices acadêmicos.

\begin{tabular}{|l|c|c|c|c|c|c|c|c|}
\hline Medidas / Componente & CBI & CBE & FP & PCC & PEQ/ES* & OPT & NPC & IQD \\
\hline Média & 74,3 & 76,6 & 82,6 & 84,7 & 87,8 & 83,1 & 79,1 & 0,73 \\
\hline Mediana & 74,2 & 77,0 & 82,7 & 85,0 & 87,5 & 82,1 & 78,7 & 0,77 \\
\hline Moda & 73,0 & 70,6 & 77,5 & 76,9 & 87,5 & 78,3 & 78,7 & 1,00 \\
\hline Mínimo & 62,2 & 62,4 & 68,7 & 71,0 & 77,5 & 69,3 & 67,7 & 0,28 \\
\hline Máximo & 93,2 & 92,0 & 95,0 & 98,5 & 98,0 & 95,0 & 102,1 & 1,00 \\
\hline Desvio padrão & 6,8 & 7,6 & 5,8 & 5,5 & 5,2 & 6,8 & 6,6 & 0,2 \\
\hline
\end{tabular}

*No fluxo 2008.2, o estágio supervisionado é avaliado por conceito, não por nota.

Fonte: Elaboração própria baseada nos dados do Histórico Escolar de Graduação.

Os professores tiveram melhor desempenho em PEQ/ES (87,8 pontos) e PCC (84,7 pontos), indicando resultados mais satisfatórios na formação prática concedida no

\footnotetext{
${ }^{3}$ Em todos os cursos de graduação da instituição, considera-se aprovado em uma disciplina o estudante que obteve, no mínimo, a média de NPC (70 pontos) em uma escala de nota que varia entre 0 e 100 pontos. Caso ele tenha nota inferior a 70 pontos, e não seja inferior a 40 pontos, deve se submeter ao Exame Final, que gera a Nota de Exame Final (NEF). Caso ele necessite deste exame para ser aprovado, a soma entre NPC e NEF deve ser igual ou superior a 50 pontos.

${ }^{4} \mathrm{O}$ IQD varia de 0 a 1 , sendo atribuído 1 a cada estudante de graduação da instituição no início de sua trajetória acadêmica. À medida que o estudante progride participando das atividades no curso, o valor do seu IQD pode ou não ser alterado, a depender do rendimento em relação aos créditos obtidos, considerando reprovação por nota ou falta de assiduidade e trancamento de disciplina.
} 
curso, corroborando que a formação nessa área foi melhor do que na área específica de Química. Esse desempenho também esteve próximo ao obtido na FP (84,6 pontos) e nas disciplinas optativas (OPT) (83,1 pontos), confirmando melhor resultado na área educacional, sendo os componentes específicos da área de Ciências da Natureza aqueles com resultados inferiores, representados por CBI (74,3 pontos) e CBE (76,6 pontos).

A Figura 3 complementa a informação sobre o desempenho e elucida o rendimento no curso, em função da média geral de NPC e da qualificação discente.

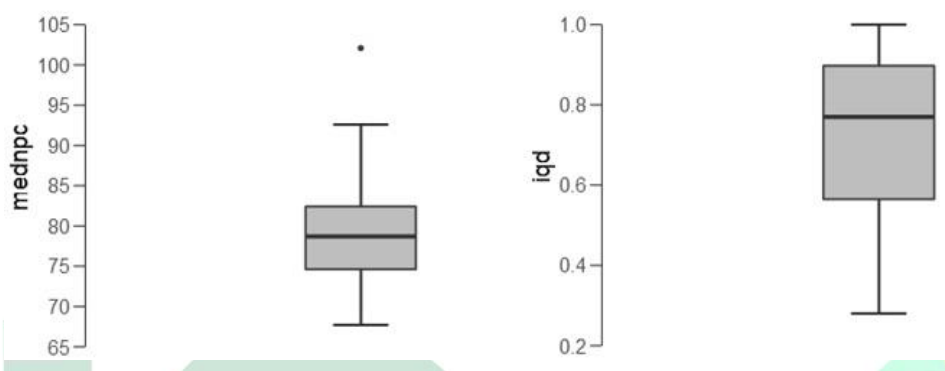

Figura 3 - Distribuição quartílica do NPC e do IQD.

Fonte: Elaboração própria com auxílio do Jasp 0.8.6.0®, baseada nos dados do Histórico Escolar.

O desempenho e o rendimento dos egressos foram satisfatórios, uma vez que eles se formaram com assiduidade e quase nenhuma reprovação, indicado por um IQD cuja média é 0,73 e está próxima de sua mediana. Também superaram a média de NPC estabelecida nos cursos de graduação da instituição, em termos de média das médias (79,1 pontos), que apresentou regularidade (achatamento do box-plot), sobretudo nas áreas específicas de formação docente (FP, PCC e PEQ/ES).

Embora a maioria deles se sinta indecisa no que diz respeito à formação profissional obtida no curso, seu desempenho leva a crê que a formação inicial exerceu forte influência sobre o desenvolvimento profissional, bem como foi determinante para escolha da profissão docente (NÓVOA; 1999), inclusive na área de Química (SÁ; SANTOS, 2016). Tal dedução pôde ser embasada pela opinião satisfatória dos sujeitos da pesquisa sobre as atividades realizadas em disciplinas ligadas ao Ensino de Química, seja pela preparação profissional, articulação entre teoria e prática e aulas práticas de laboratório (aproximadamente $89 \%$, cada) ou atividades de pesquisa (78\%), fatos semelhantes a outras pesquisas envolvendo cursos de licenciatura em Química (SILVA; OLIVEIRA, 2009; SÁ; SANTOS, 2016).

\subsubsection{Formação continuada}


Do total de respondentes, $75,9 \%$ realizou formação continuada, sendo uma característica de sua constituição profissional. Destes, a maioria $(77,5 \%)$ não conseguiu afastamento do trabalho, mesmo para cursos oferecidos pelas instituições educacionais públicas nas quais possui vínculo empregatício (40\%), ou para realizar cursos oferecidos pelo setor privado e não vinculado à instituição educacional que trabalham (31\%). Ainda assim, conseguiram obter títulos como especialista (44,4\%), mestre $(11,1 \%)$ e doutor $(9,3 \%)$, sendo que o restante $(25,9 \%)$ possui somente a graduação.

Os dados indicam que os professores que apresentam maior titulação em nível de pós-graduação tendem a se afastar ou não permanecer na docência na Educação Básica. Isto se intensifica na área de Química ou em áreas afins, em que existem outras oportunidades profissionais, inclusive para licenciados, como a pesquisa científica/ acadêmica, os laboratórios de análise química, a indústria etc. (SILVA; OLIVEIRA, 2009; MALDANER, 2013). A Figura 4 mostra as áreas de conhecimentos que os professores realizaram cursos lato e stricto sensu.

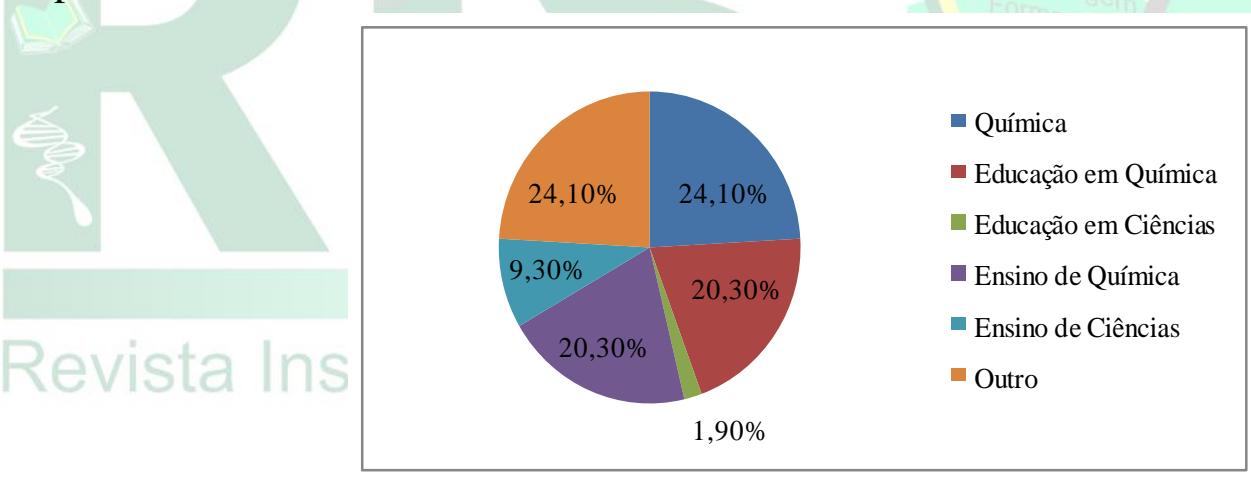

Figura 4 - Áreas de conhecimento.

Fonte: Elaboração própria baseada nos dados do questionário eletrônico.

A maioria $(48,2 \%)$ optou por realizar formação continuada na área de Química ou em outra área, seguido da área de Educação e Ensino de Química (40,6\%). Os resultados demonstram que é possível seguir a carreira docente na mesma área da graduação, complementando o binômio formação-atuação, potencializando a docência em Ciências/Química na Educação Básica e progredindo na carreira docente, visando melhorias na profissão como valorização social e manutenção de progressão e percentual de aumento salarial (CASTRO; CARVALHO, 2019).

\subsubsection{Exercício docente}


As últimas variáveis analisadas são relativas às características do trabalho docente em função da experiência e vínculo na Educação Básica e de especificidades da prática docente como jornada de trabalho, instituições educacionais em que se atua e saberes docentes teóricos e práticos mobilizados na docência.

A Figura 5 mostra o tempo de atuação dos sujeitos da pesquisa na Educação Básica como docente.

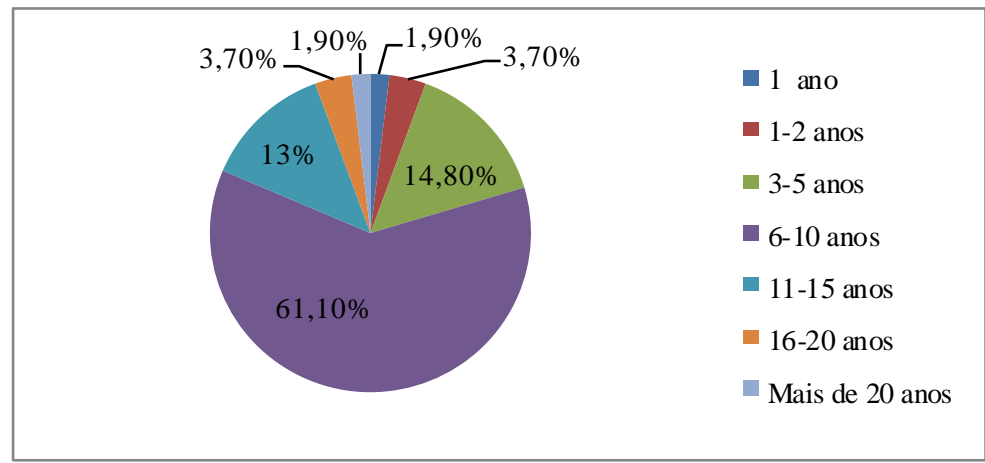

Figura 5 - Período de docência na educação básica.

Fonte: Elaboração própria baseada nos dados do questionário eletrônico.

A maioria dos professores (79\%) encerrou a fase inicial de experiência na Educação Básica, ou seja, já passou pelos anos iniciais de docência, se concentrando em quase uma década de experiência $(61,10 \%)$, seguidos daqueles que iniciaram a segunda década (13\%). A minoria encontra-se nos anos iniciais ou com mais experiência (6\%, cada). Esses dados permitem inferir que ampla maioria dos docentes começa a se estabilizar na profissão, superando as dificuldades impostas a profissionais que se encontram em início de carreira (HUBERMAN, 1995).

Sobre as disciplinas que lecionam nesse nível de ensino, a predominância é Química no Ensino Médio Regular (57,4\%), seguida de Ciências no Ensino Fundamental (27,8\%), Química no Ensino Fundamental e Ensino Médio integrado com o Técnico (14,8\%, cada) e Química no Ensino Médio Profissionalizante (4\%). É importante destacar que percentual significativo de professores ministra disciplinas diferentes das quais foram habilitados $(22,2 \%)$ e, portanto, apresenta distorção entre formação inicial e atuação profissional, algo que vem sendo tratado pelo Instituto Nacional de Estudos e Pesquisas Educacionais Anísio Teixeira (INEP, 2014) como um desafio a ser enfrentando pelo atual Plano Nacional de Educação (PNE 2014 - 2024). 
Com exceção de dois professores $(3,7 \%)$, os demais atuam exclusivamente na Educação Básica, com vínculo temporário no serviço público da rede estadual de educação (37\%), seguidos daqueles que são efetivos na mesma rede $(30 \%)$ ou na rede municipal $(17 \%)$, os que atuam na rede particular $(11 \%)$, e como temporários no município (4\%). Destarte, a união dos vínculos efetivos no serviço público estadual e municipal representa quase metade da situação profissional dos professores (47\%). No entanto, é importante destacar que 53\% possuí vínculo precário no magistério e, assim, apresenta maior dificuldade em prosseguir na carreira docente, realizando um trabalho em regime temporário, geralmente em substituição a professores efetivos que se encontram afastados do serviço por algum tipo de licença. Sobre esse problema, Tardif e Lessard (2014) e Nóvoa (1992) defendem que o magistério não deve ser encarado apenas como um ofício para o qual as exigências são bastante flexíveis, mas que este trabalho se converta em profissão.

Sobre a jornada de trabalho em instituições educacionais, a maioria (80\%) dos docentes atua somente em uma instituição educacional, predominantemente em escola de ensino regular (78\%), com uma carga horária de 40 horas semanais (56\%), seguida dos que trabalham semanalmente entre 20 e 39 horas (24\%), mais de 40 horas (11\%) e menos de 20 horas (9\%). Os principais turnos de trabalho são manhã e tarde (89\%), mas há os que trabalham a noite $(11 \%)$. Ademais, a maioria (78\%) tem residência no mesmo município em que está localizada a escola em que atuam. O restante (22\%) precisa se deslocar para trabalhar, percorrendo distâncias entre 15 Km e 166 Km.

Analisando estes dados, identifica-se que, de modo geral, a dinâmica de trabalho dos professores pode ser considerada normal no sentido de não os sobrecarregar cotidianamente. No entanto, é necessária atenção para a natureza das atividades que eles realizam, se estão ligadas a prática de ensino ou são demandas sob a lógica de políticas educacionais que contribuem com a precarização do trabalho docente (OLIVEIRA, 2004), como avaliações externas em larga escala em demasia.

A Figura 6 apresenta os modos pelos quais os professores adquiriram seus saberes docentes (teóricos e práticos).

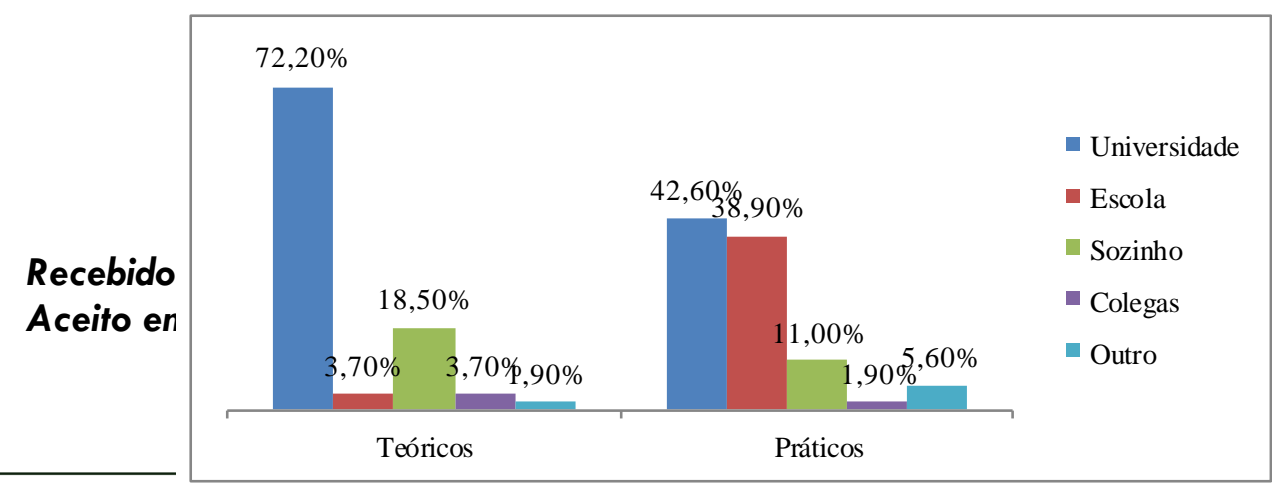


Figura 6 - Modo de aquisição de saberes docentes.

Fonte: Elaboração própria baseada nos dados do questionário eletrônico.

Os saberes docentes teóricos e práticos foram obtidos, principalmente, no curso de licenciatura em Química, com destaque para os conhecimentos específicos e pedagógicos relativos à Química e seu ensino (72,2\%). A aquisição de saberes práticos foi obtida, principalmente, na universidade $(42,6 \%)$ e na escola $(38,9 \%)$, indicando ser necessária uma aproximação profícua entre esses espaços formativos para afirmação da profissão docente (NÓVOA, 2017).

Os professores informaram que os principais fatores associados ao bom desempenho de sua profissão, os quais requerem a mobilização de vários saberes, são: planejamento pedagógico (43\%); domínio do conteúdo a ser ensinado (36\%); identidade pessoal e relacionamento com os alunos (10,5\%, cada). Essa lógica é respaldada por Tardif (2002) quando afirma que os saberes docentes são habilidades e competências indispensáveis ao ensino e de natureza múltipla, sendo adquiridos em distintos ciclos de vida.

Portanto, os momentos nos quais os professores vivenciam sua profissão em diversos espaços, a exemplo da universidade e da escola, são propícios para a aquisição de múltiplos saberes, que tendem a mobilizar o exercício profissional na medida em que o professor interage com outros membros da comunidade escolar (TARDIF; LESSARD, 2014). No entanto, para o bom desempenho da profissão, Carvalho e GilPerez (2011) orientam que seja considerado, inicialmente, o conhecimento da disciplina a ser ensinada (fator secundário na visão dos sujeitos). 


\section{CONCLUSÃO}

Identificar um perfil dos docentes fornece indícios sobre a compreensão de como se envereda pela carreira do magistério, pela descrição de alguns dos períodos determinantes do aprendizado profissional desses sujeitos. Isto tende a viabilizar melhorias no ensino, na formação inicial do professor e no trabalho que ele realiza rotineiramente. É sabido que, dentre outros, formação e trabalho docentes são elementos estruturantes da docência como profissão, estimulando candidatos a se engajarem profissionalmente com o ensino.

Para a maioria dos professores considerados, as experiências de vida anteriores ao ingresso no curso de graduação não serviram como indícios de identificação com a docência. No entanto, para os outros, alguns momentos ocorridos nos ambientes familiar e escolar foram fundamentais na escolha da profissão docente. $\mathrm{O}$ fator preponderante para a escolha desta profissão entre os que assim assinalaram, foi o gosto por disciplinas da área de Ciências da Natureza, o que influenciou a realização de vestibular em curso de tal área, resultando em desempenho satisfatório em provas específicas como Biologia e Química.

Igualmente importante, a socialização secundária dos sujeitos pesquisados permitiu a continuidade do seu desenvolvimento profissional, por meio de formação docente (inicial e continuada) que lhe preparou e capacitou para o ensino na Educação Básica e, consequentemente, no aperfeiçoamento do exercício docente. Eles atribuíram às suas experiências formativas e profissionais grande influência no seu processo de constituição docente, pois além de terem adquirido formação específica e, principalmente, pedagógica satisfatórias, conferidas por meio de seu desempenho e rendimento acadêmicos, continuam se capacitando em áreas afins da graduação, bem como se desenvolvendo profissionalmente por meio do exercício docente no âmbito da Educação Básica.

Entretanto, análises sobre o momento fulcral na constituição profissional (licenciatura) permitiram inferir que a docência é condicionada, em grande medida, por experiências procedentes da prática do ensino de Ciências/Química. Isto sinaliza a necessidade de integração curricular entre as áreas específica e pedagógica no curso, como vem sendo proposto nacionalmente nas últimas décadas (BRASIL, 2002a, 2015, 
2019), estabelecendo uma cultura de profissionalização que reverberará, inclusive, no trabalho docente promovido pelos professores formadores.

Investigações sobre o egresso da licenciatura que atua como professor são relevantes, auxiliando na descrição dos constituintes de sua profissão, destacando-os em um contexto real. Por meio do aferido em função das aprendizagens pré-profissional e profissional, a sistematização do "tornar-se professor" poderá subsidiar estudos mais aprofundados que se coadunam a essa temática.

\section{REFERÊNCIAS}

BRASIL. MEC. Parâmetros Curriculares Nacionais para o Ensino Fundamental. Brasília, MEC/SEF, 1997. Disponível em: portal.mec.gov.br/seb/arquivos/pdf/ livro01.pdf. Acessado em: 14 abr. 2021.

BRASIL. MEC. Parâmetros Nacionais Curriculares Ensino Médio: bases legais. Brasília, DF: MEC, 2000. Disponível em: portal.mec.gov.br/setec/arquivos/ pdf/BasesLegais.pdf>. Acessado em: 14 abr. 2021.

BRASIL. MEC. CNE. Parecer CNE/CES n ${ }^{\circ}$ 1.303, de 04 de dezembro de 2001. Estabelece as Diretrizes Curriculares Nacionais para os cursos de Química. Portal MEC. Brasília, DF: MEC/CNE/CES, 2001. Disponível em: portal.mec.gov.br/cne/arquivos/ pdf/CES1303.pdf. Acessado em: 14 abr. 2021.

BRASIL. MEC. CNE. Resolução CNE/CP No 1 de 18 de fevereiro de 2002a. Institui Diretrizes Curriculares Nacionais para a Formação de Professores da Educação Básica, em nível superior, curso de licenciatura, de graduação plena. Portal MEC. Brasília, DF: MEC/CNE/CP, 2002. Disponível em: portal.mec.gov.br/cne/arquivos/pdf/rcp01 _02.pdf>. Acessado em: 07 fev. 2021.

BRASIL. MEC. CNE. Resolução CNE/CP No 2 de 19 de fevereiro de 2002b. Institui a duração e a carga horária dos cursos de licenciatura, de graduação plena, de formação de professores da Educação Básica em nível superior. Portal MEC. Brasília, DF: MEC/CNE/CP, 2002. Disponível em: portal.mec.gov.br/cne/arquivos/pdf/ CP022002.pdf. Acessado em: 03 fev. 2021.

BRASIL. MEC. SEMET. PCN+ Ensino Médio: orientações complementares aos Parâmetros Curriculares Nacionais - ciências da natureza, matemática e suas tecnologias. Brasília, DF: MEC/Semtec, 2002c. Disponível em: PCN E PCN + Ensino Médio (mec.gov.br). Acessado em: 21 mar. 2021.

BRASIL. MEC. SEB. Orientações curriculares para o ensino médio: ciências da natureza, matemática e suas tecnologias. Brasília, DF: MEC/SEB, 2006. v. 2. 
Disponível em: portal.mec.gov.br/seb/arquivos/pdf/book_volume_02_internet.pdf. Acessado em: 10 abr. 2021.

BRASIL. MEC. CNE. Resolução CNE/CP No 2 de 1 de julho de 2015. Define as Diretrizes Curriculares Nacionais para a formação inicial em nível superior (cursos de licenciatura, cursos de formação pedagógica para graduados e cursos de segunda licenciatura) e para a formação continuada. Portal MEC. Brasília, DF: MEC/CNE/CP, 2015. Disponível em: pronacampo.mec.gov.br/images/pdf/res_cne_cp_02_030720 15.pdf>. Acessado em 28 jan. 2021.

BRASIL. Base Nacional Comum Curricular: Ensino Médio. Brasília: MEC/Secretaria de Educação Básica, 2018. Disponível em: basenacionalcomum.mec.gov.br/abase. Acessado em 14 abr. 2021.

BRASIL. MEC. CNE. Resolução CNE/CP No 2 de 20 de dezembro de 2019. Define as Diretrizes Curriculares Nacionais para a Formação Inicial de Professores para a Educação Básica e institui a Base Nacional Comum para a Formação Inicial de Professores da Educação Básica (BNC-Formação). Portal MEC. Brasília, DF: MEC/CNE/CP, 2019. Disponível em: portal.mec.gov.br/docman/dezembro-2019pdf/135951-rcp002-19. Acessado em: 02 fev. 2021.

CACHAPUZ, A.; GIL-PÉREZ, D.; CARVALHO, A.M.P.; PRAIA, J.; VILCHES, A. (orgs.). A necessária renovação do ensino das ciências. $3^{a}$ ed. São Paulo: Cortez, 2011.

CARVALHO, A. M. P.; GIL-PÉREZ, D. Formação de professores de Ciências: tendências e inovações. 10. ed. São Paulo: Cortez, 2011.

CASTRO, J. J. M.; CARVALHO, F. A. F. Configuração e atratividade da carreira docente da educação básica do município de Cametá/PA. Educação \& Formação, v. 4, n. 10, p. 164-179, 2019.

CHASSOT, A. Alfabetização científica: questões e desafios para a educação. $8^{a}$ ed. Ijuí: Ed. Unijuí, 2018.

DUBAR, C. A socialização. Construção das identidades sociais e profissionais. São Paulo: Martins Fontes, 2005.

DUBAR, C. A construção de si pela atividade de trabalho: a socialização profissional. Tradução MACDADO, F. Cadernos de pesquisa, v. 42, n. 146, p. 351-367, 2012.

FIGUEIRA-OLIVEIRA, D.; DO ANJOS, M.; RÔÇAS, G. A biograficidade em curso: como os Professores se tornaram Professores. Revista Insignare Scientia - RIS, v. 3, n. 5, p. 45-59, 2020.

HUBERMAN, M. O ciclo de vida profissional dos professores. In: NÓVOA, A. (org.). Vidas de professores. 2 ed. Portugal: Porto Editora, 1995. p. 31-61. 
INSTITUTO NACIONAL DE ESTUDOS E PESQUISAS EDUCACIONAIS ANÍSIO TEIXEIRA (INEP). Nota técnica No 02002014. Brasília: Inep, 2014. Disponível em: < http://download.inep.gov.br/educacao_basica/prova_brasil_saeb/resultados/2013/nota_t ecnica_indicador_de_adequacao_da_formacao_do_docente_da_educacao_basica.pdf $>$. Acessado em: 10 jan. 2021.

LEVIN, J.; FOX, J. A.; FORDE, J. A. Estatística para ciências humanas. 11 ed. São Paulo: Pearson Education do Brasil, 2012.

MALDANER, O. A. A Formação Inicial e Continuada de Professores de Química. Professores/pesquisadores. 3ª ed. Ijuí: Ed. Unijuí, 2013.

NASCIMENTO, M. A. V. F. P. A Construção da Identidade Profissional na Formação Inicial de Professores. 453f. Dissertação (Doutoramento em Ciências da Educação na especialidade de Formação de Professores) - Faculdade de Psicologia e de Ciências da Educação, Universidade de Coimbra, Coimbra, 2002.

NÓVOA, A. (coord.). "Os professores e a sua formação". Lisboa: Dom Quixote, 1992.

NÓVOA, A. O passado e o presente dos professores. In: NÓVOA, A. Profissão professor. Porto: Porto Editora, 1999. p. 13-34.

NÓVOA, A. Firmar a posição como professor, afirmar a profissão docente. Cadernos de Pesquisa, v. 47, n. 166, p. 1106-1133, 2017.

OLIVEIRA, D. A. A reestruturação do trabalho docente. Precarização e flexibilização. Educação \& Sociedade, Campinas, v. 25, n. 89, p. 1127-1144, 2004.

RADETZKE, S. F. O escrever reflexivo na constituição do Ser Professor. Revista Insignare Scientia - RIS, v. 1, n. 3, p. 1-13, 2019.

SÁ, C. S. S.; SANTOS, W. L. P. Motivação para a carreira docente e construção de identidades: O papel dos pesquisadores em ensino de química. Química Nova, v. 39, n. 1, p. 104-111, 2016.

SAMPIERI, R. H.; COLLADO, C. F.; LUCIO, M. P. B. Metodologia de pesquisa. 5 ed. Porto Alegre: Penso, 2013.

SILVA, C. S.; OLIVEIRA, L. A. A. Formação inicial de professores de Química: formação específica e pedagógica. In: NARDI, R. (org.). Ensino de ciências e matemática, I: temas sobre a formação de professores [online]. São Paulo: Editora UNESP, 2009. p. 43-57.

STAKE, R. The art of case study research. Thousands Oaks: Sage, 1995 
TARDIF, M. Saberes docentes e formação profissional. $4^{\mathrm{a}}$ Ed. Rio de Janeiro: Vozes, 2002.

TARDIF, M.; LESSARD, C. O trabalho docente: elementos para uma teoria da docência como profissão de interações humanas. $9^{\mathrm{a}}$ ed. Petrópolis: Vozes, 2014.

TARDIF, M.; RAYMOND, D. Saberes, tempo e aprendizagem no trabalho no magistério. Educação e Sociedade, Campinas, n. 73, p.209-244, 2000.

YIN, R. K. Estudo de caso: planejamento e métodos. Tradução Cristhian Matheus Herrera. 5. ed. Porto Alegre: Bookman, 2015.

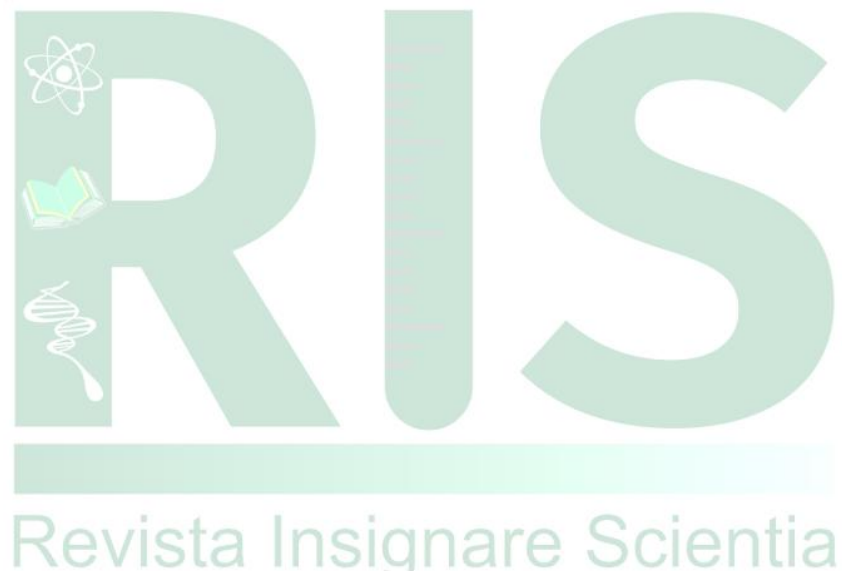

